\title{
Unusual Cause of Trigeminal Neuralgia: Arachnoid Cyst of Petrous Apex
}

\author{
S. El Fakir, M. Ouha, Y. Zouine, L. El Assasse, S. Alj \\ Department of Radiology, Ibn Tofail Hospital, Mohamed VI University Hospital, Cadi Ayad University, Marrakech, Morocco \\ Email:sophia.efk@gmail.com
}

How to cite this paper: El Fakir, S., Ouha, M., Zouine, Y., El Assasse, L. and Alj, S. (2019) Unusual Cause of Trigeminal Neuralgia: Arachnoid Cyst of Petrous Apex. Open Access Library Journal, 6: e5807. https://doi.org/10.4236/oalib.1105807

Received: September 22, 2019

Accepted: November 5, 2019

Published: November 8, 2019

Copyright $\odot 2019$ by author(s) and Open Access Library Inc.

This work is licensed under the Creative Commons Attribution International License (CC BY 4.0).

http://creativecommons.org/licenses/by/4.0/

(c) (i) Open Access

\begin{abstract}
Arachnoid cyst of petrous apex is an uncommon cyst lesion that herniates from the posterolateral portion of the Meckel's cave into the petrous apex. It can be unilateral or bilateral, usually observed in female population. Its etiopathogenesis is still uncertain and many theories were reported in the literature. The characteristic imaging appearance, topography and benign behavior of the lesion allow to differentiate arachnoid cyst from other cyst-like lesions of petrous apex and prevent abusive surgery or unnecessary investigations. The purpose of this study is to illustrate through this observation the role of sectional imaging in the diagnosis of symptomatic arachnoid cyst of petrous apex.
\end{abstract}

\section{Subject Areas}

Radiology \& Medical Imaging

\section{Keywords}

Arachnoid Cyst, Petrous Apex, Meckel's Cave, Trigeminal Neuralgia

\section{Introduction}

Arachnoid cyst of petrous apex is a hernia of the posterolateral wall of Meckel's cave into the petrous apex. It is an unusual cyst lesion, incidentally detected most of the times; however it can be symptomatic often revelated by trigeminal neuralgia.

CT scan and MRI imaging features allow positive diagnosis of arachnoid cyst of petrous apex and distinguish it from other benign lesions of petrous apex namely inflammatory lesions revealing from surgery.

We report a case of a patient suffering from trigeminal neuralgia secondary to 
anarachnoid cyst of petrous apex.

The purpose of this study is to illustrate through this observation the role of sectional imaging in the diagnosis of symptomatic arachnoid cyst of petrous apex.

\section{Case Report}

We report a case of a 67 years-old woman, followed for diabetes and high blood pressure, complained currently of headache with right hemiface spasm and facial hypoesthesia of the ipsilateral trigeminal nerve interesting territories of V1 and V2 without peripheral facial palsy, trigger zone or mixed nerves involvement associated.

Brain MRI was performed. Figure 1 shows a bilateral extra axial cyst lesion, centered on posterolateral portion of the Meckel's cave, bigger on the right side measured $16 \times 12 \mathrm{~mm}$ on the right and $7 \times 6 \mathrm{~mm}$ on the left. Their content was homogeneous like the cerebrospinal fluid signal; in low signal intensity on T1 weighted FSE, and high signal intensity on T2 weighted FSE attenuated on Flair, with high apparent coefficient of diffusion (ADC), without enhancement, containing thin partition drafts. A bilateral arachnoid cyst of petrous apex was suspected. We noted also the association with arachnoidocele.

A CT-scan complement was performed. Figure 2 shows a bilateral well defined, smooth expansive and non-invasive bony lesion of the petrous apex centered on the posterolateral portion of Meckel's cave, smoothly eroding the right carotid canal with a normal pneumatization of middle ear and mastoid cells.

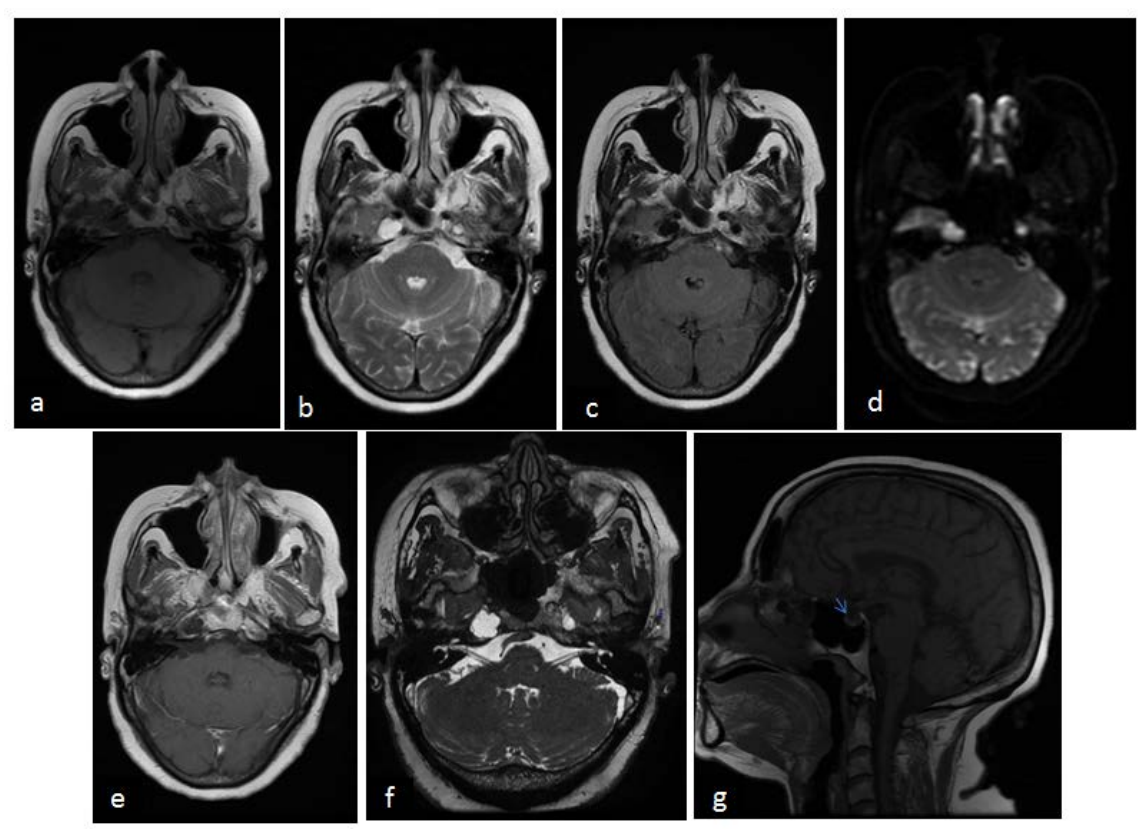

Figure 1. MRI images in axial plan in T1 weighted FSE (a), T2 weighted FSE (b), Flair (c), diffusion (d), T1 with contrast (e), Fiesta (f) and in sagittal plan (g). Bilateral expansive cyst lesion, centered on posterolateral part of Meckel's cave and extended to petrous apex. It has lobulated borders with CSF-like signal. It is associated to an arachnoidocele. 

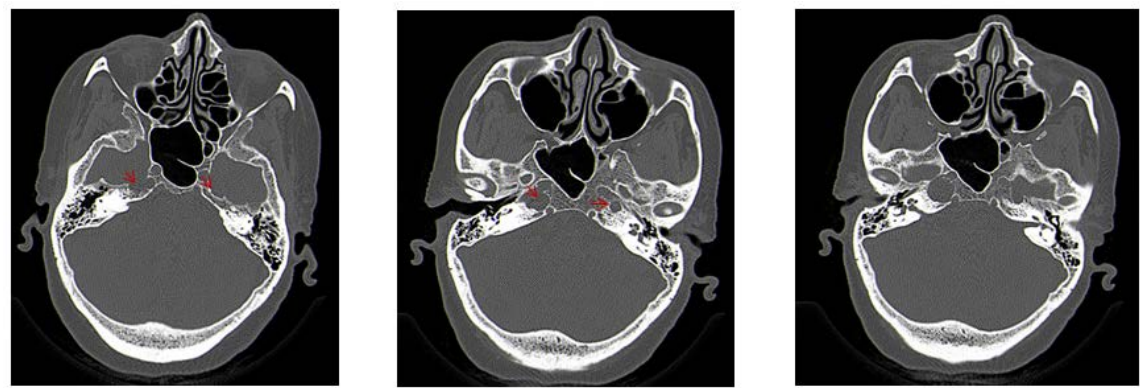

Figure 2. CT-scan images in axial plan. Bilateral expansive lesion of petrous apex with scalloped border eroding smoothly the right carotid canal. We noted a normal pneumatization of middles ears and mastoids cells.

CT-scan results confirmed the diagnosis of bilateralarachnoid cystof petrous apex.

\section{Discussion}

\subsection{Generalities}

Trigeminal neuralgia is a debilitating disease. Its secondary form is due to any damage to the path of the fifth cranial pair by direct attack or extrinsic compression [1]. Arachnoid cyst of petrous apex is one of the rarest causes of trigeminal neuralgia. It is an uncommon cyst lesion defined by a hernia of the posterolateral wall of Meckel's cave into the petrous apex [1] [2]. Arachnoid cyst is often asymptomatic and fortuitously discovered. sometimes it can be revealed by trigeminal neuropathy with neuralgia or paraesthesia and headache such as in our observation or responsible of leakage of cerebrospinal fluid in the form of otorrhea that is manifested by sensorineural hearing loss and may necessitate surgical treatment [3].

This pathological entity is often bilateral and encountered in female population. Because of its rarity of clinical expression, previous conducted studies have focused on small samples, therefore, they can't allow for statistical inferences [4] [5].

\subsection{Etiopathogenesis}

The exact etiopathogenesis of arachnoid cyst remains not well understood; congenital and acquired mechanisms have both been proposed [2]. It is usually associated with empty Sella, such as in our observation and especially in several reports suggesting the same etiopathogenesis [4] [5]. The most widely accepted theory is that of altered cerebrospinal fluid dynamics with increased intracranial pressure which subsequently leads to herniation of meninges and cerebrospinal fluid from the posterolateral portion of Meckel's cave into the petrous apex [3] [4] [6] [7].

\subsection{Positive Diagnosis}

Cross sectional imaging allows the diagnosis. On CT-scan, the arachnoid cyst of 
petrous apex presents as a well-defined hypodense and avascular lesion with lobulated or rounded edges, located behind the Meckel's cave and smoothly eroding the petrous apex without marginal sclerosis or calcifications. It displaces neurovascular elements and erodes adjacent bone structures such as carotid canal. On MRI, the arachnoid cyst of petrous apex is a lobulated cyst lesion demonstrate a CSF-like signal; hypo signal T1 weighted FSE, in hypersignal T2 weighted FSE, attenuated on Flair with a high apparent diffusion coefficient without enhancement after contrast injection. Thin trabeculations can be individual within it [8] [9] [10].

\subsection{Differential Diagnosis}

The diagnosis of arachnoid cyst of petrous apex should be properly made and differentiated from other cyst lesions to avoid abusive surgical treatment or unnecessary controls. Hence, sectional imaging features are useful to distinguish arachnoid cyst of petrous apex from others cyst-like lesions in the same location. Topographically arachnoid cyst arises from postero-lateral wall of Meckel's cave and secondary erode into the petrous apex, whereas lesions such as cholesteatoma, cholesterol granuloma, mucocele, apical porosities and petrous apex effusion, arise from the petrous apex and expand it from within and secondary reach Meckel's cave [2] [8]. The low intensity signal on T1 weighted FSE of the arachnoid cyst allows to distinguish it from the cholesterol granuloma which is in hypersignal T1 weighted FSE. Cholesteatoma has a high signal on Flair and diffusion with a low apparent diffusion coefficient unlike arachnoid cyst of petrous apex. Enhancement and non-aggressive character distinguish arachnoid cyst of petrous apex from other infectious lesions [8] [9] [10].

Cephalocele is a generic term described by Moore that referred to arachnoid cyst, meningocele and meningoencephalocele of petrous apex. MRI can usually identify herniated brain elements referring to meningoencephalocele. However, it is difficult to differentiate meningocele from an arachnoid cyst by imaging and only anatomopathological analysis allows it to ascertain the presence of a dural lining in meningocele and its absence in arachnoid cyst [2].

\subsection{Treatment}

Generally, arachnoid cyst of petrous apexis is often asymptomatic and incidentally discovered on brain MR images. It does not require any specific treatment and some cases in the literature have reported its spontaneous resolution [11].

Because of anatomical wealth of this region, surgical intervention should be approached cautiously and undertaken only when symptoms are clearly linked to the presence of this lesion and not responding to symptomatic treatment. In our case, clinical symptomatology was controlled by medical treatment and surgery was not currently indicated.

\section{Conclusions}

Arachnoid cyst of petrous apex should be considered in patients with trigeminal 
involvement, especially trigeminal neuralgia. It is less common than inflammatory cystic petrous apex lesions arising from complications of air cell disease.

The distinctive imaging appearance and topography of arachnoid cyst allow the radiologist to make this diagnosis with a high degree of certainty which is important to avoid any misdiagnosis of these lesions leading to an unnecessary surgery.

\section{Conflicts of Interest}

The authors declare no conflicts of interest regarding the publication of this paper.

\section{References}

[1] Leclercq, D., Thiebaut, J.-B. and Héran, F. (2013) Névralgie du trijumeau. Diagnostic and Interventional Radiology, 94, 1000-1008. https://doi.org/10.1016/j.jradio.2013.07.005

[2] Moore, K.R., Fischbein, N.J., Ric Harnsberger, H., Shelton, C., Glastonbury, C.M., White, D.K. amd Dillon, W.P. (2001) Petrous Apex Cephaloceles. American Journal of Neuroradiology, 22, 1867-1871.

[3] Çavusoglu, M., Duran, S., Hatipoglu, H.G., Cllız, D.S., Elverici, E. and Sakman, B. (2015) Petrous Apex Cephalocoele: Contribution of Coexisting Intracranial Pathologies to the Aetiopathogenesis. The British Journal of Radiology, 88, Article ID: 20140721. https://doi.org/10.1259/bjr.20140721

[4] Alorainy, I.A. (2007) Petrous Apex Cephalocele and Empty Sella: Is There Any Relation? European Journal of Radiology, 62, 378-384. https://doi.org/10.1016/j.ejrad.2007.01.010

[5] Hatipoglu, H.G., Cetin, M.A., Gürses, M.A., Daglioglu, E., Sakman, B. and Yüksel, E. (2010) Petrous Apex Cephalocele and Empty Sella/Arachnoid Cyst Coexistence: A Clue for Cerebrospinal Fluid Pressure Imbalance? Diagnostic and Interventional Radiology, 16, 7-9. https://doi.org/10.4261/1305-3825.DIR.2650-09.2

[6] Isaacson, B., Coker, N.J., Vrabec, J.T., Yoshor, D. and Oghalai, J.S. (2006) Invasive Cerebrospinal Fluid Cysts and Cephaloceles of the Petrous Apex. Otology \& Neurotology, 27, 1131-1141. https://doi.org/10.1097/01.mao.0000244353.26954.71

[7] Jeong, B., Lee, G., Shim, J., Lee, J., Nam, M. and Kyun, H. (2011) Petrous Apex Cephalocele: Report of Two Cases and Review of the Literature. Journal of the Korean Society of Radiology, 64, 439-443. https://doi.org/10.3348/jksr.2011.64.5.439

[8] Alkilic-Genauzeau, I., Boukobza, M., Lot, G., George, B. and Merland, J.J. (2007) Aspects TDM et IRM du kyste arachnoidien de l'apex petreux. Journal of Radiology, 88, 1179-1183. https://doi.org/10.1016/S0221-0363(07)89930-6

[9] Batra, A., Tripathi, R.P., Singh, A.K. and Tatke, M. (2002) Petrous Apex Arachnoid Cyst Extending into Meckel's Cave. India Australasian Radiology, 46, 295-298. https://doi.org/10.1046/j.1440-1673.2002.01063.x

[10] Chapman, Ph.R., Ritu, S., Cure, J.K. and Bag, A.K. (2011) Petrous Apex Lesions: Pictorial Review. American Journal of Roentgenology, 196, WS26-WS37. https://doi.org/10.2214/AJR.10.7229

[11] Jacob, M., Gujar, S., Trobe, J. and Gandhi, D. (2008) Spontaneous Resolution of a Meckel's Cave Arachnoid Cyst Causing Sixth Cranial Nerve Palsy. Journal of Neuro-Ophthalmology, 28, 186-191. https://doi.org/10.1097/WNO.0b013e318183be6c 